\title{
Potential benefits of satiety to the consumer: scientific considerations
}

\author{
M. M. Hetherington ${ }^{1}$, K. Cunningham ${ }^{2}$, L. Dye ${ }^{1}$, E. L. Gibson ${ }^{3}$, N. T. Gregersen ${ }^{4}$, \\ J. C. G. Halford ${ }^{5}$, C. L. Lawton ${ }^{1}$, A. Lluch ${ }^{6}$, D. J. Mela ${ }^{7}$ and H. C. M. Van Trijp ${ }^{8}$ \\ ${ }^{1}$ Institute of Psychological Sciences, University of Leeds, Leeds, UK \\ ${ }^{2}$ Coca-Cola Europe, Hammersmith, London, UK \\ ${ }^{3}$ University of Roehampton London, London, UK \\ ${ }^{4}$ University of Copenhagen, Copenhagen, Denmark \\ ${ }^{5}$ University of Liverpool, Liverpool, UK \\ ${ }^{6}$ Danone, Centre Daniel Carasso, Palaiseau, France \\ ${ }^{7}$ Unilever RED Vlaardingen, Vlaardingen, The Netherlands \\ ${ }^{8}$ Wageningen University, Wageningen, The Netherlands
}

\begin{abstract}
Foods and dietary patterns that enhance satiety may provide benefit to consumers. The aim of the present review was to describe, consider and evaluate research on potential benefits of enhanced satiety. The proposal that enhanced satiety could only benefit consumers by a direct effect on food intake should be rejected. Instead, it is proposed that there is a variety of routes through which enhanced satiety could (indirectly) benefit dietary control or weight-management goals. The review highlights specific potential benefits of satiety, including: providing appetite control strategies for consumers generally and for those who are highly responsive to food cues; offering pleasure and satisfaction associated with low-energy/healthier versions of foods without feeling 'deprived'; reducing dysphoric mood associated with hunger especially during energy restriction; and improved compliance with healthy eating or weight-management efforts. There is convincing evidence of short-term satiety benefits, but only probable evidence for longer-term benefits to hunger management, possible evidence of benefits to mood and cognition, inadequate evidence that satiety enhancement can promote weight loss, and no evidence on which consumers would benefit most from satiety enhancement. The appetite-reducing effects of specific foods or diets will be much more subtle than those of pharmaceutical compounds in managing hunger; nevertheless, the experience of pharmacology in producing weight loss via effects on appetite suggests that there is potential benefit of satiety enhancement from foods incorporated into the diet to the consumer.
\end{abstract}

Key words: Satiety: Appetite: Hunger: Food patterns: Weight management

Consumers are interested in obtaining benefits from the foods they consume and express a willingness to change their diet for health reasons ${ }^{(1)}$. Concerns about body weight and preventing CVD are amongst their top health considerations. In addition, consumers are interested in purchasing and consuming products supported by claims regarding satiety or feelings of fullness ${ }^{(2)}$. Manufacturers confirm that data from (proprietary, unpublished) market research has supported the commercial development of products with benefits for appetite control, with consumers indicating that hunger feelings are a major reason for failed weight-loss attempts ${ }^{(3)}$, and that modulating this can contribute toward weight-management strategies ${ }^{(4)}$.
Thus, in response to consumer interest, food companies are developing products with varying claims about the satiety-enhancing effects of particular foods. Examples of such claims are illustrated in Table 1.

Despite increased innovation and claims activity regarding satiety and appetite control, the value of these claims and the evidence required to support them are issues of considerable debate ${ }^{(5-10)}$. The European Food Safety Authority ${ }^{(11)}$ under article $13 / 5$ states that 'Scientific substantiation should be the main aspect to be taken into account for the use of nutrition and health claims... A claim should be scientifically substantiated by taking into account the totality of the available scientific data, and by

Abbreviations: CCK, cholecystokinin; DFF, d-fenfluramine; PYY, peptide tyrosine tyrosine. 
Table 1. Examples of claims made by manufacturers to promote their foods and beverages within the satiety enhancement space

\begin{tabular}{ll}
\hline Food product & Claim \\
\hline Nutrition shake & $\begin{array}{c}\text { 'Freedom from hunger' } \\
\text { 'Ranilla milkshake }\end{array}$ \\
$\begin{array}{l}\text { 'Runger and cravings' } \\
\text { 'Helps satisfy your hunger' }\end{array}$ \\
Oatmeal, cereal, milkshakes & $\begin{array}{l}\text { 'Feel fuller for longer' } \\
\text { Yoghurt, ready-to-eat meals }\end{array}$ \\
$\begin{array}{l}\text { Egg protein } \\
\text { Protein shake }\end{array}$ & 'Fill me up'; 'keep me going to \\
& prevent hunger' \\
\hline
\end{tabular}

weighing the evidence' (section 17), but further requires applicants to 'ensure that the substances for which a claim is made have been shown to have a beneficial nutritional or physiological effect' (section 14). There is a growing consensus over the appropriate methodologies for assessing effects of foods on satiety and appetite control ${ }^{(12)}$, and thus the scientific basis for satiety claims substantiation. However, even where such effects of foods have been adequately substantiated, one of the key unsettled issues is the (health) benefit that such effects - whether delivered through 'traditional' foods and diets or specially designed products - could confer to the consumer.

Given the large academic research effort related to determinants of satiety, it is reasonable to reflect on the evidence for the potential impacts this could have. Food companies are furthermore specially challenged to justify that foods carrying substantiated satiety claims convey a consumer benefit, especially if only acute behavioural effects have been demonstrated. Foods that enhance fullness and help to control hunger have the potential to provide benefits to the consumer in many different ways, including those related to longer-term weight management. However, Blundell ${ }^{(5)}$ cautions that: "The wording of a claim is, therefore, critical. The difference between a proof of concept and a guarantee of success is an important point that needs to be conveyed to the consumer.' (p. 53) Components of foods that strengthen satiety signals may have clear substantiation from laboratory-based studies in the short term, but there is uncertainty over whether and how enhancing satiety effects of foods as a general principle translates to physiological or health benefits to the consumer, such as in managing hunger or maintaining a healthy diet.

It is reasonable to propose possible benefits to the consumer of foods that enhance satiety and these include:

(a) Providing appetite control strategies for consumers who are highly responsive to the food environment and eat opportunistically;

(b) Offering pleasure and satisfaction associated with low-energy/healthier versions of food products without feeling 'deprived';

(c) Reducing dysphoric mood states associated with feeling hungry especially during periods of energy restriction; (d) Increasing feelings of subjective wellbeing, maintaining or preventing a decline in cognitive function associated with skipping meals or lowered energy intakes;

(e) Improving the ability to cope with fluctuations in hunger over the day;

(f) Improving compliance with healthy eating targets and weight-management efforts;

(g) Increasing self-efficacy through adherence to diet goals;

(h) Achieving weight loss and preventing weight (re)gain, maintaining a healthy body weight and reducing risk of weight regain.

Therefore, possible benefits of enhanced satiety are diverse ranging from short-term considerations such as early termination of a meal and reduced overall energy intake to longer-term benefits such as helping consumers to achieve dietary goals (see Fig. 1).

Amongst the many putative benefits of satiety enhancement, a key long-term benefit may be assisting in weight loss. For example, perceived hunger has been shown to predict failure to lose weight in clinical trials ${ }^{(13)}$; and perceived deprivation is linked to susceptibility to weight gain ${ }^{(14)}$. Providing consumers with guidance on dietary patterns and products that offer pleasure, satisfaction and a means to manage hunger could confer benefit. Foods can be chosen or their characteristics manipulated in order to promote satiation within a meal such as altering the orosensory stimulation involved in consuming single foods ${ }^{(15)}$, to promote satiety by increasing the fibre or protein content of individual foods or beverages ${ }^{(16-18)}$ or by including several of these products to benefit the overall diet (Fig. 1). A significant conceptual gap remains between evidence gathered in highly controlled contexts such as the experimental laboratory and claims made about satiety enhancement in the context of the day-to-day lives of the consumer.

Evidence to support or refute these potential benefits has yet to be scrutinised; therefore, the main aim of the present review is to describe, consider and evaluate research on potential benefits of enhanced satiety and appetite control in the short, medium and long term.

The review was conducted by a panel of experts who are internationally recognised in their field of expertise. The task articulated to the panel was to consider the evidence on 'benefits of satiety' in its widest interpretation. A systematic review process was not suitable because of the known paucity of papers directly addressing these questions as a primary research goal. Setting rigid inclusion criteria would have been difficult, and severely limited the scope of evidence that the expert panel could consider. However, the primary sources of data were randomised, controlled intervention studies published in refereed journals. Where relevant, the panel also assessed the overall 


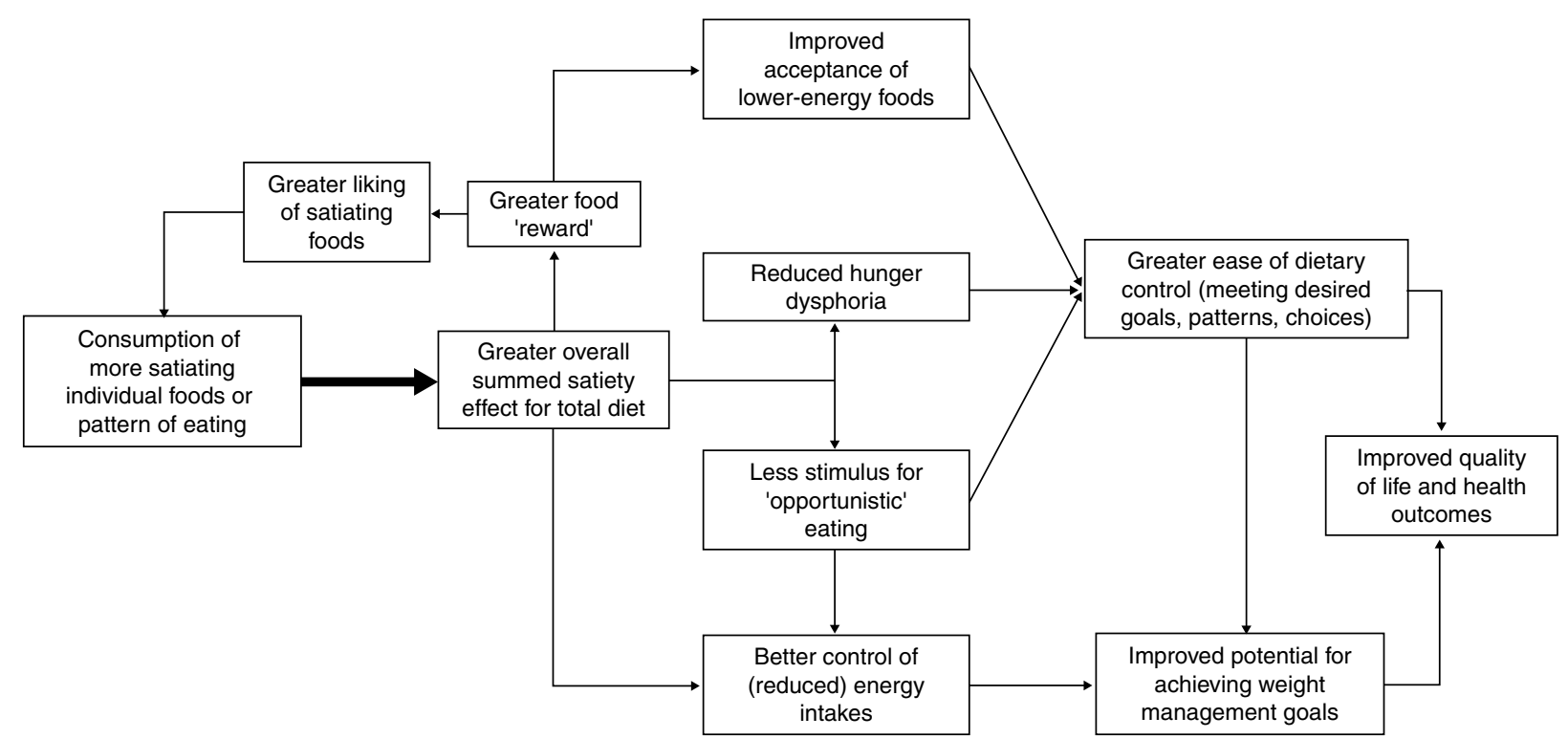

Fig. 1. Schematic illustration of the potential routes to end-benefits from incorporation of more satiating individual foods within an overall dietary pattern. A key aspect is that, in contrast to the single and simplistic notion that enhanced satiety only benefits consumers by a direct effect on food intake, this highlights various routes through which enhanced satiety could (indirectly) lead to increased dietary control in general or improved success in meeting active weight-management goals specifically. The reasoning and evidence related to these different routes are addressed in the various sections of the present review.

weight and quality of evidence as 'convincing', 'probable', 'possible' or 'inadequate'.

\section{The consumer perspective}

Consumers are encouraged to eat a healthy diet containing a variety of foods and beverages that help achieve and maintain a healthy weight, promote health and prevent disease. Diets that contain whole grains, fruits and vegetables, that are relatively high in fibre and low in energy density, tend to promote satisfaction and satiety. Specifically developed products with added satiety benefits hold market potential to the extent that consumers may be willing to try these products, purchase repeatedly and include them in habitual consumption (Fig. 1). Products with a claimed satiety benefit share some features of foods with other health benefits, but differ on a number of key parameters. Firstly, most health benefits of foods are accrued over a relatively long time whereas for satiety-enhancing foods the timeframe to learn the association between specific foods and their effects on reducing hunger and/or increasing or prolonging fullness is apparent within a short timescale. Also, where the satiety benefit is intended to reduce consumption and ultimately to assist in weight management (maintenance or weight loss), this longerterm end-effect can also be directly monitored by the consumer, unlike, for example, cholesterol lowering. Together, these two features provide a strong basis for learning from personal experience ${ }^{(19)}$, provided that satiety-enhancing foods deliver on these benefits.

However, in the specific context of satiety-enhancing foods the benefit to the consumer will depend upon individual differences in response to satiety enhancement.
Thus, food developed to enhance satiety may reduce subjective hunger and eating motivations during the day; however, the consumer may elect to override these signals.

Managing food intake is a complex process that requires self-regulation and self-control in the face of environmental pressures to overconsume. By definition, foods that enhance satiety hold the potential to delay the onset of the next eating episode (satiety power: affecting the decision about whether and when to eat again) and/or curtail the ongoing eating episode (satiation power: affecting how much to eat). Both of these effects, crucial to sustained consumer responsiveness to the product, critically depend on the balance between consumer sensitivity to signals arising from the internal/physiological environment $v$. the external environment; and individual differences in how this balance is achieved.

Research on sensitivity to internal $v$. external cues as a basis of food choice has a long history within Psychological Science, ever since Schachter's 'internal-external' theory of eating (see Herman \& Polivy ${ }^{(20)}$, for an historical account of this theory). With increased interest in the obesogenic environment, the distinction between sensitivity to external $v$. internal cues has been revived. Several attempts have been made to quantify individual differences such as the extent to which individuals are sensitive to internal $v$. external satiety signals. The Dutch Eating Behavior Questionnaire $^{(21)}$ contains a subscale for external eating; this measures the consumer's responsiveness to foodrelated stimuli, regardless of the internal states of hunger and satiety. More recently, the Power of Food Scale has been developed ${ }^{(22,23)}$ to 'assess the psychological impact of living in food abundant environments - as reflected in feelings of being controlled by food, independent of 
food consumption itself ${ }^{\text {(23) }}$ (p. 914). This scale is not an instrument for responsiveness to internal cues (referred to as homeostatic hunger), but rather is a measure of 'hedonic hunger' ${ }^{(24)}$ : 'the extent to which individuals are affected by food even when eating is not imminent or underway $^{\text {(24) }}$ (p. 437).

Qualitative research on consumer views of hunger and fullness ${ }^{(25)}$ confirms that consumers do not have detailed views of what hunger and satiety mean, and the subjective indicators from which they can be assessed. Consumers use a variety of internal (for example, presence or absence of hunger pains) and external (for example, my plate is clean) cues to assess their subjective experiences of hunger and fullness. This is particularly important when considering food intake management that requires both self-control and therefore cognitive resources. Self-control processes involve three steps: (a) setting a goal (limiting food intake); (b) monitoring progress; and (c) taking appropriate action. Enhanced satiety signals provide an internal benchmark against which progress can be monitored during consumption, but there is reason to believe that both the goal setting (consumption norms) and monitoring processes are easily overridden by external cues in the consumption environment ${ }^{(26)}$. This is particularly true when cognitive resources are limited ${ }^{(27)}$ or attention is otherwise distracted from the eating situation and internal signals ${ }^{(28,29)}$; the so-called state of mindless eating ${ }^{(30)}$. Along these lines, Framson et al. ${ }^{(31)}$ developed the Mindful Eating Questionnaire to reflect 'a nonjudgmental awareness of physical and emotional sensations while eating or in a food related environment' (p. 1439); also Tylka ${ }^{(32)}$ has produced an 'Intuitive Eating Scale' which assesses patterns of eating based on physiological hunger and satiety (internal) more than situational (external) cues. These instruments have potential utility in understanding which consumers might benefit most from satietyenhanced dietary patterns and products and to determine whether or not a potential benefit of satiety is to help resist temptations to overeat in vulnerable individuals, or to augment flexible restraint ${ }^{(33)}$.

In terms of effective positioning and labelling to induce consumer responsiveness, prior research suggests that motivation and ability are key factors determining consumers' systematic processing of the message (for example, Petty \& Cacioppo $\left.{ }^{(34)}\right)$. Motivation depends on personal relevance. Building on research on health claim acceptance among consumers (for example, Drichoutis et $a l^{(35)}$ and Pothoulakim \& Chryssochoidis ${ }^{(36)}$ ), a consistent finding is that consumers who already experience a health-related problem are most receptive to products addressing that specific health condition. In the context of satiety-enhancing foods, it is clear that consumers already experiencing overweight problems (or at least a concern with weight maintenance) will be a target group. Nutritional knowledge may enhance responsiveness to products with a health claim ${ }^{(36)}$, posing a challenge to convince those consumers least involved and knowledgeable about nutrition and health links. Market research seems to suggest that consumers are confused with existing satiety claims in the market place ${ }^{(37)}$. However, in a recent survey, 1504 consumers across Europe asked about satiety claims correctly understood this to mean assisting with hunger management and not providing a 'magic bullet' for weight $\operatorname{loss}^{(38)}$. Nevertheless, restrained eaters were more likely to over-interpret satiety claims but across weight categories the importance of personal responsibility for weight loss was acknowledged ${ }^{(38)}$. Overall, more research is needed on consumer understanding of nutrition and health claims including those made for satiety ${ }^{(39)}$.

Nutrition-specific concepts such as awareness of the diet-disease relationship and concern about nutrition and health show a consistent relationship with responsiveness to product claims ${ }^{(38,39)}$. These variables provide a potentially strong basis for segmentation on responsiveness to products with a satiety benefit, although from a public health perspective these knowledgeable consumers may not be the primary target, given the socioeconomic gradient in unhealthy diets and the expression of obesity ${ }^{(40,41)}$.

Research by Van Trijp \& Van der Lans ${ }^{(42)}$ suggests that for satiety-enhancement claims it is important to provide a 'reason to believe' underlying the health benefit ('this yoghurt helps you keep feeling full'). However, as for most other health claims, consumer responsiveness does not differ very much between this being expressed as a nutrition claim (contains fibre) or a disease risk-related context. This may be attributable to the fact that fibre is a well-established satiety-related ingredient to most consumers.

Overall, there is limited existing research on how the wording of satiety-related claims would influence consumer responsiveness and at present the evidence base is inadequate. Some segments of the population may benefit more than others from satiety enhancement but this suggestion needs to be explored further with tools available to characterise particular consumer behaviours such as restrained eating, externality, mindfulness, health orientation and/or intuitive eating. The area is worth pursuing in order to clarify to consumers the meaning of a satietyenhancing product and to relay the potential benefits that this may confer to specific groups of consumers.

\section{Potential benefits of pleasure: liking and reward}

Satiety enhancement generally occurs in the context of a meal, with consequences for that meal and/or the next. An enjoyable meal is one that combines optimal sensory pleasure, in the context of a suitable level of hunger at the outset, with a fully satisfying level of repletion (for that individual in that context). Pleasant feelings, or at least satisfaction or good mood, perhaps induced by pleasant memories of the meal (see below), may follow for $1 \mathrm{~h}$ 
or more after such a meal, provided that over-satiation has been avoided. In referring to satisfaction, pleasure and enjoyment, we are acknowledging that eating food is, normally, fundamentally rewarding to the brain ${ }^{(43)}$. It is recognised that there is an ongoing debate as to whether purely hedonic sensory pleasure ('liking') can be meaningfully separated from expressions of reward-based motivation ('wanting') ${ }^{(44-46)}$. Here we take the parsimonious view that, in most human studies, both measures typically capture 'appetite', with any differences most probably reflecting semantic and contextual influences on participants' interpretation rather than separable brain outputs $^{(44)}$ : a rating of pleasantness of a food can be at least as much an acquired appetitive response dependent on internal and external contexts as a rating of desire to eat that food. Of course, 'desire to eat' is not the same as 'sensory pleasure'; it is just that most simple measures do not clearly distinguish between them ${ }^{(47)}$.

The intention here is to consider the implications of hunger, its satiation, and satiety, on enjoyment and choice of food, and predictions for amounts eaten. Thus, the enjoyment of food is:

(a) positively related to the extent of concurrent energy (or needed nutrient) depletion, and therefore, normally, to hunger ('Cibi condimentum esse famem' ('Hunger is seasoning for food') - Cicero (106-43 BC), De Finibus Bonorum et Malorum II. xxviii);

(b) positively related to the time elapsed since eating that, or similar, food (see, by way of comparison, sensoryspecific satiety) ${ }^{(48)}$

(c) experienced as anticipatory pleasure from the sight and smell, or even thought (memory), of soon-to-be-eaten food ${ }^{(49)}$;

(d) acquired from learned anticipation of the satiating effects of a food, or meal (reinforcement from relief of hunger by energy ${ }^{(50)}$.

The first two points primarily concern early responses to the sensory experiences of eating, although they may differ in mechanisms: point (a) reflects neurohormonal signals (for example, leptin, cannabinoids, opioids, ghrelin, orexigenic peptides, vagal afferents) that enhance central pathways (for example, dopamine) mediating salience, motivation, reward, in response to acute energy-restriction signals, for example, adenosine triphosphate depletion in the liver - i.e. the 'hungry brain',51). Point (b) may be in part a form of sensory adaptation, involving cranial nerves and sensory relays, but also central brainstem, mesolimbic and cortico-limbic pathways involved in arousal, salience and memory ${ }^{(52)}$. Conceivably, afferent information from nutrient and 'taste' receptors in the upper gut could also be involved. Point (c) is under the influence of points (a) and (b), but also depends on prior experience (i.e. learning) of the food and its consequences (and orbitofrontal cortex-insular-limbic system links). Point (d) reflects the fact that the energy from a food or meal is the primary reinforcer of liking for that food ${ }^{(50,53,54)}$ : greater energy typically translates into greater satiety, although substantial uncoupling of energy from other aspects of meal size (volume, weight) can modify this relationship ${ }^{(55)}$. All four aspects should predict food choice.

With experience, the pleasure or reward from eating, especially of meal-type foods, to a large extent reflects the learned anticipation that the food being eaten will deliver effective satiety, or relief from hunger, via (principally) energy repletion ${ }^{(56,57)}$ (see point (d) above): it is the process of removal of appetite by food in the context of signals of nutrient repletion that the brain finds so rewarding ${ }^{(58)}$. By contrast, habitual consumption of sweet drinks, particularly of low-energy 'diet' versions, may rely partly on reinforcement through slating of thirst ${ }^{(59)}$, or pharmacologically via caffeine, or even by pairing with other energy intake, rather than substantive satiation ${ }^{(60)}$. Nevertheless, sweetness appears to retain a high hedonic value (even without energy) and is a strong reinforcer for the acceptance of flavours paired with it, provided that hunger is present ${ }^{(61)}$.

\section{Early enjoyment $v$. the lingering satisfaction from eating}

At the start of a meal, if the initial sensory contact with the food is pleasant, there is usually a transient stimulation of appetite (or hunger), or at least a delay in its decline, known as the 'appetiser effect' ${ }^{(62)}$. However, when enhanced energy content is disguised - mismatching expectation and experience - meal size is suppressed independently of the 'appetiser effect' ${ }^{\prime(63)}$. In other words, this early-meal appetitive response is at least partly a learned expectation of satiation, in response to orosensory stimuli that predict particular consequences. Although this was an artificial experiment, it does reflect a situation that may be relevant to attempts to promote satiation and satiety, i.e. a manipulation that enhances satiation without appreciably altering sensory properties and palatability. Thus, it is important to consider how a meal may provide pleasure, or reward, through satisfying hunger, in the context of normal habitual eating.

As a meal is eaten, early signals of energy and nutrient delivery arise, predicted and orchestrated by orosensory metering, gastric distension, vagal afferent and gut hormone activation. These signals allow the brain to anticipate the subsequent repletion of need, so that a meal can end with satisfactory feelings of satiation after only $10-15 \mathrm{~min}$, when gastric distension is high but perhaps only 80-200 kJ of food have entered the duodenum from the stomach ${ }^{(64)}$.

Recent evidence suggests that many consumers select (amounts of) foods on the basis of anticipated satiety benefits, i.e. choosing smaller (volume) portion sizes of foods expected to deliver more fullness per $\mathrm{kJ}^{(65)}$, or, in other words, how satisfying eating that food would be. 
Moreover, Brunstrom \& Rogers ${ }^{(65)}$ found that individuals gave more value to (but did not like more) foods with this higher energy-adjusted 'expected satiation'. This reflects the learned anticipation of the satisfaction that a portion of food will deliver, based on habitual experience with such foods. Thus, given the chance, individuals will choose foods that provide them with just the right level of satisfaction for the context. What is not clear is how the consumer might adapt in the long term? Would benefits of satiety enhancement be sustained over time?

When participants ate two training meals of fixed amounts, each of differently flavoured high- and lowenergy versions of porridge on separate days, they subsequently ate more (mass) only of the low-energy version compared with intake at the pre-training meal, suggesting learnt de-satiation, i.e. they recognised that specific flavour as less satiating ${ }^{(66)}$. Interestingly, their liking for this less satiating version increased; however, this could reflect a relative dislike, or aversion, to the high-energy porridge of which they had had to eat a fixed amount (perhaps too much) during training. Similarly, other data suggest that individuals more readily compensate by increasing consumption of flavours predicting lower energy, and presumably less satiation, than by decreasing the amount eaten of flavours linked to higher energy ${ }^{(67,68)}$. However, these effects refer to weight or volume of food eaten, not energy.

In contrast, in an experiment where fixed portions of a reduced-energy version of spaghetti Bolognese $(374 \mathrm{kcal}$ (1564 kJ) per $400 \mathrm{~g}$ ) were consumed over five consecutive lunches, ratings of taste declined relative to those eating a 'standard' (567 kcal $(2372 \mathrm{~kJ})$ per $400 \mathrm{~g})$ version ${ }^{(69)}$. On the other hand, ratings of expected satiety (relative delayed hunger, adjusted for energy) and satiation (relative fullness, adjusted for energy) did not differ between versions and remained unchanged (in both groups) over this time. This latter result may be encouraging for long-term maintenance of energy intake. Energy-adjusted expected satiation is a better predictor of energy portion size than is liking (though liking can predict ideal portion weight) ${ }^{(70)}$.

To understand long-term benefits from the balance of food reward and satiation effects, one must consider the relationship between satiety, inter-meal interval and enjoyment of food. Although it has been shown experimentally with fixed intakes that the amount eaten rather than the pleasantness of taste of a soup is what determines postprandial satiety ${ }^{(71)}$, one consequence of eating a meal that leads to prolonged satiety is that there will be a longer delay before hunger is again high enough to enhance the enjoyment of eating once more. For example, it is known that postprandial hormones signalling repletion of nutritional state such as insulin, leptin, glucagon-like peptide- 1 and peptide tyrosine tyrosine (PYY) can inhibit reward circuitry in the brain ${ }^{(72-74)}$, whereas conversely, when hungry, the orexigenic preprandial hormone, ghrelin, may enhance activity of reward pathways and thus the appetitive value of food ${ }^{(75)}$. This may mean that the next meal, taken more because of scheduling than need, is less enjoyable than it might otherwise be. This could be avoided if a non-energy-dependent satietyenhancing mechanism is deployed: that is, the 'holy grail' of satiation science may be to achieve a meal that satiates more strongly than its energy value, or sensory indicators, would otherwise allow, leading to a relatively 'premature' meal end. As well as curtailing within-meal energy intake, this would have the advantage of achieving greater pleasure from the subsequent meal, if by that time the energy shortfall has been detected, and appetite is stimulated. However, it is not known if repeated consumption of such foods would result in compensation for the smaller (in energy) first meal, unless that meal also allowed enhanced satiation.

On the other hand, if satiety is prolonged, yet a scheduled meal is eaten despite lack of hunger, the reduction in reward from that subsequent meal could lead to an adapting down of either meal size or frequency, so aiding weight loss or maintenance. Even sweetness becomes less reinforcing when sated, as evidenced by variation in learned liking for sweetness-odour pairings (flavour-flavour learning) ${ }^{(76)}$, and flavours associated with fat- or carbohydrate-rich energy become less appetising ${ }^{(56,57)}$. Thus, suitably balanced satiety, involving only moderate energy repletion but other mechanisms to promote satiety, should be an effective means of encouraging healthy regulation of eating.

Finally, how does enhancing satiation, and thus shortening the eating experience, influence the learned and remembered pleasure of the meal? It turns out that remembered pleasure from eating a meal suffers from 'duration neglect' - a phenomenon from pain research where the affective memory of a painful experience is minimally influenced by its actual duration ${ }^{(48)}$. Thus, in a Chinese buffet meal, doubling the amount of a favourite component made no difference to either the immediate or delayed recall of meal liking ${ }^{(77)}$. This is encouraging from the perspective of reducing meal size, as it suggests that eating a smaller amount of an enjoyable food encodes as pleasant a memory as eating a larger amount.

In summary, there is convincing evidence that hunger, as characterised by appetite arising from an energy deficit, increases the pleasure of eating energy-rich foods. There is probable evidence that properties of foods, such as volume, that contribute to expected satiety or satiation independently from their energy value, predict how much (energy) of a food is chosen, and more reliably than does general liking. This implies that such properties will be important for weight maintenance, though may not be central to the pleasure of eating. However, evidence from more chronic studies is limited, so that benefits of longer-term manipulations of satiety for the pleasures of eating may be possible, but are not yet convincingly demonstrated. 


\section{Potential benefits for short-term hunger management}

Several studies have assessed the relationship between self-reported eating motivations and subsequent food intake. These have evaluated short- and long-term effects, and most ${ }^{(78-86)}$, though not all ${ }^{(87)}$, have found statistically significant relationships, in the expected directions. One explanation for the relatively low correlations reported is that energy intake over time is generally driven by energy expenditure, which is largely a characteristic of the individual, and that food intake at any single meal has many non-physiological determinants. Despite this, most analyses find a significant effect of self-reported eating motivations, typically explaining at least 10\% of variance in intakes.

A related question is how much change in eating motivations is needed in order to have a consistently meaningful effect. Veldhorst et $a l .{ }^{(86)}$ proposed that a difference of 15 to $25 \mathrm{~mm}$ on a $100 \mathrm{~mm}$ visual analogue scale is necessary to observe a significant difference in energy intake at a subsequent meal. They demonstrated that varying the protein content of breakfasts produced changes in subjective satiety of about $40 \%$, which were then correlated with subsequent reductions in energy intake at lunch. This proposal is supported by a meta-analysis of twenty-five studies by Sadoul et $a l^{(88)}$ indicating that a change of about $15 \mathrm{~mm}$ or more on a $100 \mathrm{~mm}$ scale was associated with consistent and significant changes in food intake.

Reduced eating motivation is also a primary mode of action of a number of pharmaceutical approaches proposed and applied for the management of obesity, which have met criteria for long-term efficacy ${ }^{(89)}$. By definition, foods with an added satiety effect reduce explicit eating motivations, which may by itself be a benefit for consumers. Although the appetite-reducing effects of specific foods or diets will probably be less potent than drugs, it is also reasonable to assume some degree of doseresponsiveness; that is, even small increases in satiety should be beneficial in the ease and success in control of eating. The effects of such drugs on eating motivations and behaviour are known and have been related to efficacy $^{(90,91)}$. During periods of negative energy balance, appetite increases along with a number of physiological mediators that together act against sustained reductions in energy intake ${ }^{(92-94)}$. Consistent with this, measures of perceived hunger have been found to be inversely related to 'ease' and outcomes in weight-loss trials ${ }^{(13,81,95)}$

\section{Potential benefits to mood and cognitive function: reducing hunger dysphoria}

Dietary patterns and products that enhance satiety and aid in appetite control may produce benefits to the consumer in relation to the reduction of hunger-related dysphoria (see Fig. 1). These beneficial effects of foods or drinks on mood may also affect cognitive performance. Mood state is known to modulate cognitive function ${ }^{(96)}$; however, the direction of the relationship is not straightforward ${ }^{(97)}$. Other research has documented effects of food on cognitive function in the absence of alterations in mood and direct mechanisms of action, for example, via alterations in glucose availability or nutrient-induced synthesis of neurotransmitters (see Gibson \& Green ${ }^{(97)}$ and Dye \& Blundell $^{(98)}$ ).

Despite the potential for satiety enhancement to improve affect and in turn to influence cognitive function, there are only four published studies that have measured satiety concurrently with objective measures of cognitive function ${ }^{(99-102)}$. Lloyd et al. ${ }^{(99,100)}$ studied the effects of low-fat/high-carbohydrate, medium-fat/medium-carbohydrate and high-fat/low-carbohydrate isoenergetic breakfasts and lunches in two similarly designed studies on mood, appetite and cognitive performance. In the breakfast study, a no-breakfast condition was also included and no differences in satiety were found in the breakfast or the lunch study. There were no effects of any breakfast on cognitive performance. However, the medium-fat/ medium-carbohydrate lunch, which was similar in energy and macronutrient composition to the habitual lunches of the participants, was associated with faster reaction times than following the low-fat/high-carbohydrate and high-fat/low-carbohydrate lunches. The authors concluded that a medium-fat/medium-carbohydrate (habitual composition) lunch might be preferred because this nutrient profile optimises mood and mental performance after lunch. In contrast, Wells \& $\operatorname{Read}^{(102)}$ observed little change in cognitive performance and no change in hunger/satiation following lower-energy high-fat/lowcarbohydrate and higher-energy low-fat/high-carbohydrate meals consumed either mid-morning or at lunchtime in eighteen healthy males. Wells et al. ${ }^{(101)}$ adopted a different approach and found that intraduodenal infusions of dietary lipid (Intralipid; Kabi Pharmacia) significantly reduced speed and accuracy of performance on a sustained attention task in five male volunteers compared with an isotonic saline control. This postprandial decline in performance occurred with concomitant decreases in hunger over the early part of the morning. The authors concluded that fat exerts a greater depression on subjective alertness than carbohydrate irrespective of a reduction in energy content.

Studies that have assessed cognitive function have seldom measured or reported measures of satiety. Hence any effect of satiety on cognitive function can only be inferred on the basis of features of the foods consumed rather than via directly measured effects. Of the few studies that have examined cognitive performance and appetite simultaneously ${ }^{(99-102)}$, subjective satiety was not associated with effects on cognitive performance. Effects observed appear to depend on the time of day that the food is eaten with any effects less evident at lunchtime. Meals that more closely resemble the habitual diet of the consumer appear to be associated with optimum 
performance ${ }^{(99)}$. Often studies of the effects of foods on cognitive function consider foods or macronutrients in isolation and with little relevance or reference to the satiating properties of these foods ${ }^{(103)}$. It could be suggested that feelings of fullness are associated with a slowing of mental performance or that hunger might stimulate performance to a degree and be detrimental if the state was enduring. However, there is much to be done to understand how satiety enhancement might benefit the consumer in relation to changes in mood, and specifically how benefits to mood and cognition become associated with the habitual diet over time. Overall, the benefit of satiety to cognition remains a possibility but the evidence is currently inadequate.

\section{Further potential benefits of satiety: meeting dietary goals}

Another area of potential benefit of satiety enhancement is the extent to which this can aid dietary goal adherence, including achieving a healthy diet. Enhanced satiety reduces hunger with potential benefits for mood and cognition. It is known that hunger and feelings of deprivation promote intrusive thoughts of food ${ }^{(104)}$ and may promote intake of unhealthy foods; it therefore follows that managing hunger has the potential to assist in adhering to dietary goals such as eating a healthier diet and avoiding overconsumption.

Managing dietary goals, such as setting out to achieve a healthier diet, is determined, in part, by self-efficacy. This is a psychological construct that refers to an individual's belief in their competence to act. Self-efficacy reflects confidence in self-mastery of specific activities, situations or aspects of psychological and social functioning ${ }^{(105)}$. Self-efficacy can be demonstrated by the extent to which consumers believe that their actions can facilitate specific health behaviours, such as achieving a healthy diet, or managing body weight. Self-efficacy predicts success in a number of different health behaviours such as readiness to increase exercise, intake of fruits and vegetables and healthy eating (for example, Pearson et al. ${ }^{(106)}$ ). The conviction that behavioural control can be successfully exerted on body weight and healthy eating may produce greater levels of success in behaviour change outcomes.

Eating self-efficacy is another potentially relevant psychological construct to benefits of satiety, illustrated by the extent to which consumers believe that they are in control of their appetite and ability to regulate food intake. Eating self-efficacy is a significant predictor of weight $\operatorname{loss}^{(107,108)}$. Consumers who believe that body weight is determined by genetics and therefore cannot easily be changed by behavioural methods lose less weight than consumers with high eating self-efficacy ${ }^{(108)}$. For consumers with high eating self-efficacy, consumption of foods that enhance satiety may be a useful adjunct to achieving goals such as healthier eating or weight loss/ maintenance (discussed in detail below).
Whilst studies have shown that higher self-efficacy predicts greater weight loss; it is not the case that weight loss per se changes self-efficacy (for example, Clark \& King $\left.{ }^{(109)}\right)$. Thus, it is useful to consider whether foods that enhance satiety by increasing feelings of fullness and satisfaction may in turn enhance eating self-efficacy. This has yet to be tested, but it is reasonable to suppose that satiety enhancement provides the consumer with an aid to meeting dietary goals through hunger management. This suggestion has been made by investigators interested in the problem of managing hunger during weight-loss interventions. For example, obese children achieving equivalent weight loss after assignment to either a standard or an isoenergetic high-protein diet reported a significant increase in desire to eat over the course of the 8-week intervention ${ }^{(110)}$. These authors identified hunger management during negative energy balance as a key problem in children's weight loss and they propose the inclusion of low-glycaemic index and high-fibre foods in the diet as a means to promote satiety.

In summary, consumers may benefit from strategies to manage hunger that also increase eating self-efficacy, and contribute to the success of behavioural goals such as achieving a healthy weight or a healthier diet. There is convincing evidence that self-efficacy influences health behaviours including weight loss and dietary intake; it is probable that hunger management contributes to selfefficacy in the context of weight management; and it is possible that satiety enhancement will assist in achieving dietary goals. However, at present the evidence is inadequate in linking together constructs such as eating self-efficacy, satiety enhancement and outcomes such as consuming a healthier diet.

\section{Achieving weight-management goals}

More is known about the potential benefits of satiety for weight management. A variety of behavioural and psychological factors are associated with successful weight control. Regular meal eating, breakfast eating, controlled snacking and adherence to a low-fat diet are behaviours that are associated with successful weight loss and weight maintenance ${ }^{(111)}$. Conversely, disinhibited eating, poorly controlled hunger, a binge eating response to negative emotions and psychosocial stressors, and difficulties in resisting social and emotional eating cues are associated with poorer weight-loss outcomes and subsequent weight regain $^{(112-115)}$. Long-term successful weight management involves sustained changes to behaviour and overcoming physiological defence mechanisms to maintain body weight. Targeting appetite using specific foods or meals can be a means of managing hunger arising from periods of energy restriction to help individuals resist the strong environmental and situational cues to overconsume. However, if satiety is to benefit weight management, the effects of energy restriction on the mechanisms underpinning 
sensations of hunger and fullness need to be elaborated. For example, as consumers change their diet in order to meet weight goals, there are changes in gastrointestinal motility, gut peptide release, and secretion of hormones such as leptin. The benefits of satiety enhancement may be to reduce the impact of emergent hunger or cravings during dieting and weight loss; however, this will depend upon physiological adaptations to the effects of energy restriction.

\section{Physiological considerations}

During periods of negative energy balance, a number of physiological mediators of energy intake may contribute toward increased frequency or intensity of dysphoric (hunger) feelings and associated difficulty of compliance with weight-control efforts. This in turn may lead to poor weight-loss success or rapid weight regain. Arguably, food-based enhancement of satiety may help to counteract these secondary effects of reduced energy intake. In this sense, satiety enhancement may affect weight control primarily by affecting the ability to cope with negative energy balance induced by any given diet plan, as a distinct alternative to directly suppressing energy intake (Fig. 1).

Ghrelin released from the stomach and to a smaller degree also from the intestines appears to play an important role in meal initiation ${ }^{(116)}$. Increased fasting ghrelin levels were seen following 7-9 weeks of dieting in morbidly obese women with and without type 2 diabetes ${ }^{(117)}$ Several studies have supported this finding ${ }^{(118-120)}$. In another study, ten healthy overweight/obese male volunteers were assigned to a very low-energy density diet for $46 \mathrm{~d}^{(121)}$, and showed an initial decrease in ghrelin levels (day 25); however, at the end of the period the ghrelin levels were significantly increased ${ }^{(121)}$, although anticipation of the end of dietary restriction may have been a factor (for example, Drazen et al. ${ }^{(122)}$ ).

Whereas ghrelin increases hunger, other peptides released primarily from proximal and distal locations in the small intestine increase satiety sensations, for example, cholecystokinin (CCK), PYY and glucagon-like peptide- $1^{(116)}$. These anorexigenic peptides elicit their effects through mechanisms inhibiting gastric emptying and direct appetitesuppressing effects on the brain ${ }^{(116)}$.

Postprandial levels of CCK have been shown to be decreased following a $10 \%$ weight loss ${ }^{(123)}$, suggesting a reduced satiating potential that could increase susceptibility to weight regain. In addition to its direct effects, CCK also acts indirectly, which is illustrated by blocking CCK-1 receptors attenuating the usual rise in PYY and concomitantly reducing the inhibition of the meal-initiation stimulus from ghrelin ${ }^{(124)}$. PYY secretion is dependent on the amounts of energy and macronutrients ingested, and short-term complete fasting has been shown to decrease PYY levels by 40-60\% from baseline ${ }^{(125)}$.
A 10-week weight-loss programme ${ }^{(94)}$ produced significant and sustained changes in a broad profile of hormones influencing meal initiation, appetite and satiety, including ghrelin, CCK and PYY. All of the changes were consistent with less inhibition (or greater stimulation) of eating motivational signals. Most of these hormonal changes, along with corresponding increases in self-reported appetite, were still apparent 1 year after the weight loss.

Overall, there is modest but consistent evidence of physiological changes during sustained negative energy balance that would tend to weaken satiety signals and promote the desire to eat. This suggests that food-based approaches intended to counteract those changes could be both justified and beneficial. However, one of the primary routes for food-based enhancement of satiety is through increased gastric distension and reduced gastrointestinal transit time. In contrast to hormonal changes, gastric capacity may be reduced during dieting ${ }^{(126)}$. Whether this reduction in gastric capacity could further augment the added efficacy of distension-based approaches to satiety enhancement during the course of weight loss is not known. Similarly, it is not known whether foods targeting one or more of the 'counterproductive' changes in appetite-related hormones would be especially beneficial within an energy-restricted diet. Knowledge of the relative value of alternative physiological satiety targets for foods is presently inadequate, and clearly of considerable interest for future research.

\section{Psychological effects of energy restriction}

Weight loss is often followed by weight regain, which results from physiological adaptations to energy restriction (see above) as well as its psychological effects on cravings, feelings of deprivation and changes to the reinforcing value of foods. Acute food deprivation increases the reinforcing value of food ${ }^{(127,128)}$, the subjective appeal of high-energy density foods and the activation of brain reward systems in response to pictures of these ${ }^{(43)}$. Sustained, hypoenergetic diets generally produce increased reports of hunger ${ }^{(94,110,114,129,130)}$ and changes in hunger in response to dieting can predict successful/unsuccessful weight maintenance ${ }^{(131)}$. Experimental studies of semistarvation demonstrate that restriction of energy intake can produce profound effects including preoccupation with food, unrelenting thoughts of food and eating, distraction and limited concentration (for example, Franklin et al ${ }^{(132)}$ ).

Interestingly, a similar preoccupation with food and eating, distractibility and poor concentration is seen during self-imposed inhibition of food intake such as dietary restraint ${ }^{(104)}$. Thus, even though restrained eaters may differ from dieters in a number of ways ${ }^{(133)}$, the psychological consequences of restricting food intake may be similar. Substantial but covert reductions in dietary energy provided for $2 \mathrm{~d}$ have been shown to induce progressive declines in reported satiety, yet with few 
of the negative mood effects commonly reported with weight-loss dieting ${ }^{(134)}$. This also suggests such effects may often reflect the psychology of (perceived) deprivation, and are more than an emergent property of the physiological effects of energy restriction.

Reducing energy intake, while controlling hunger and feelings of deprivation, may therefore hold the potential to enhance the consumer experience of weight control, by reducing food cravings and impulsive behaviours around food (see Fig. 1). While this seems intuitive, the experimental evidence for this is mixed. Dieting and restrained eating are commonly associated with increases in reported food cravings ${ }^{(135)}$, but the relationships with energy intake are not straightforward. Indeed, paradoxically, a reduction in craving and hunger has been observed with fasting and experimental very low-energy diet interventions $^{(136-138)}$. A speculative explanation for this is that strict regimens that exclude consumption of craved foods may suppress the learned habit of craving for those foods (prevention of repeated reinforcement, i.e. extinction) ${ }^{(139)}$. Managing cravings could nevertheless be therapeutically important in more typically flexible weight-control approaches, as there is evidence that food cravings may mediate the link between poorly controlled eating and body weight ${ }^{(134)}$. Also, reducing hunger can decrease the effects of impulsivity on eating behaviour ${ }^{(140)}$. Clearly, both are important to consumers who are particularly susceptible to environmental and situational cues to overeat as discussed in the Consumer perspective section above.

In addition to direct effects on eating motivations, conscious efforts to lose weight through energy restriction or avoiding specific foods during dieting are associated with changes to cognition in its broadest sense, including changes in cognitive function that may be secondary to preoccupation with thoughts of food or food cravings. For example, dieting is linked with deficits in sustained attention $^{(134)}$. Preoccupation with food associated with dieting can worsen mood and impair cognitive function pre- and post-consumption ${ }^{(148)}$. Food cravings also appear to limit cognitive resources ${ }^{(142)}$, and dietary restraint increases selective processing of appetitive cues $^{(143,144)}$. These effects may be related to perceived deprivation, as fasting also heightens attention for food stimuli $^{(145)}$. Thus, together with the evidence from covert reductions in dietary energy content, it appears that cognitive impairment and preoccupation with food can be a function of perceived deprivation rather than actual energy deficit ${ }^{(139,146)}$.

The role of the psychology of deprivation in dietinduced hunger, craving, or cognitive impairment includes the influence of physiological consequences of energy restriction. In addition to cited changes in biological signals influencing eating motivations, weight loss and energy restriction can produce changes in peripheral cortisol levels ${ }^{(93)}$ or changes in central nervous system serotonin function ${ }^{(147)}$ - systems involved in anxiety and mood, as well as body composition and appetite control. This would suggest that physiological changes due to fasting and weight loss could have important psychological consequences beyond appetite.

The evidence to date is inadequate to fully address the extent to which products that enhance satiety could offset feelings of deprivation during energy restriction for weight loss; it is also not known what physiological adaptations may occur with repeated consumption of such products for weight management. If appetite during dieting is managed effectively and feelings of deprivation replaced by those of satisfaction then the psychological effects of deprivation could be mitigated. Successful dieting can be beneficial for cognitive function as the sense of control of weight and eating behaviour increases ${ }^{(148)}$. Therefore, satiety enhancement of food products has the potential to reduce feelings of deprivation, and to enhance self-efficacy as well as control around food during periods of energy restriction. These potential psychological benefits (as opposed to direct effects on intake or energy balance) merit further testing in appropriately designed experiments.

\section{Improving weight-management outcomes}

As noted, the experience of energy restriction increases preoccupation with food and intrusive thoughts of food and eating, which inhibit concentration on usual activities. This may amplify the difficulty of adhering to a diet when confronted with unlimited access to food. Eating in response to negative emotions and psychosocial stressors is associated with weight regain. Given the impact of dieting on mood it is likely that a sense of deprivation may undermine compliance and lead to weight regain. It is therefore important to know if consumers cite appetite as a reason for difficulties with adherence and reasons for relapse in weight management, and also whether perceived improvements in appetite control or ability to control food intake can improve the weight-management experience.

The clear example of anti-obesity drugs indicates that satiety-enhancing manipulations can be useful in weight control. These compounds enhance satiety (at least in short-term tests) and produce weight loss in long-term placebo-controlled weight-management trials ${ }^{(149)}$. Although anorectic drugs achieve weight loss in obesity treatment, it is not fully understood how the eating process is influenced. Hunger management is, however, an important component of obesity treatment. In a placebo-controlled cross-over study of the effects of $28 \mathrm{~d}$ of d-fenfluramine (dFF) treatment (15 mg twice per d) on appetite and body weight, thirteen obese women kept daily records of their eating behaviour, hunger motivation, urges to eat, and feelings of control of eating while undergoing their normal daily activities ${ }^{(150)}$. Mean weight loss on dFF was significantly greater than that on placebo 
$(-2.4 v .-1.1 \mathrm{~kg})$ and this was accompanied by a significant reduction in daily hunger and improved feelings of control over eating. Regular sampling of subjective state over the course of the day, during both the early and late phases of treatment, confirmed these drug effects. These diurnal rhythms showed hunger motivation to be reduced throughout the day, and particularly before lunch, dinner and bedtime. There was also a reduction in the number of meals and snacks taken on dFF. These data suggest that anorectic drugs such as dFF can help obese individuals to gain control of their eating with knock-on benefits for body weight. Although this compound is no longer available to consumers, it is nevertheless a useful demonstration of the power of controlling appetite in the weight-management context.

More radical interventions such as those involved in obesity surgery also produce changes in appetite and alter the mechanisms underpinning appetite expression. These effects are associated with improved efficacy of some bariatric procedures ${ }^{(151,152)}$.

Despite these clear demonstrations of the importance of appetite control for the success of weight-loss interventions, literature specifically evaluating the role of appetite control in dietary interventions is limited and largely circumstantial. Perhaps the best-accepted link between diet, changes in appetite and weight control is with dietary protein. Protein is generally recognised to increase satiety compared with other macronutrients at a similar energy level ${ }^{(153,154)}$. Studies of high-protein diets on body weight and appetite demonstrate that the effects of protein enrichment of a diet on hunger and fullness can contribute to reductions in energy intake and body weight ${ }^{(155-157)}$. In the short term, increasing the protein content of diets can reduce energy intake, hunger and body mass ${ }^{(158)}$ and can sustain weight loss while providing for increased satiety $^{(159)}$. However, the effects of single macronutrients on satiety are often equivocal. The example cited earlier of children attending a summer weight-loss camp and given either a standard- or high-protein diet reported similar increases in appetite as negative energy balance developed $^{(110)}$. Thus, simply augmenting a weight-loss diet with additional protein does not always produce the expected reduction in appetite over time.

Low-energy diets directly intended to enhance satiety, such as high-fibre diets, also do not produce consistently greater weight loss ${ }^{(160-163)}$. However, evidence suggests that satiety-enhancing low-energy diets, particularly those high in fibre and complex carbohydrate, can suppress hunger and the desire to eat, and increase feelings of wellbeing ${ }^{(95,129,130,163,164)}$.

Few studies have monitored and specifically analysed satiety measures in relation to individual experience and success within the context of diets for weight loss or maintenance. Initial changes in satiety have been shown to predict energy intake and weight loss, particularly reductions in fasting hunger, prospective consumption and desire to eat ${ }^{(80,81)}$. Rodriguez-Rodriguez et al. ${ }^{(130)}$ analysed changes in subjective sensations of hunger and wellbeing reported by overweight/obese women ( $n$ 67) following one of two 6-week hypoenergetic diets (both based on restricting consumption of energy-rich foods, one encouraging the consumption of cereals, the other encouraging consumption of salad and vegetables). Subjective ratings of hunger and wellbeing were measured at various time points across the day (before and after breakfast, lunch, dinner and snacks). Hunger ratings were used to calculate the satiety quotient of each meal using the method described by Drapeau et al. ${ }^{(81)}$. A wellbeing quotient was derived by similar means (i.e. post-meal minus pre-meal wellbeing ratings divided by the energy content of the meal). Although both diets led to similar reductions in body weight, a lower dropout rate with the cereal diet was attributed to improved satiety and wellbeing.

Distinct ingredients and diets may therefore produce benefit via appetite effects even if these do not necessarily translate into notably greater weight loss. Beneficial effects may include improving the experience of dieting and increased compliance, which in turn may produce subtle improvements in the efficacy of weight-management programmes. Overall, there is convincing evidence from pharmacological studies of the importance of hunger management in achieving weight loss, and probable evidence that dietary manipulations such as increasing protein, complex carbohydrate, or fibre content of lowenergy diets contribute to hunger management and therefore to weight loss. At present the evidence to demonstrate consistently that such non-pharmacological satiety enhancement can produce significantly greater weight-loss success is, however, inadequate.

\section{Potential long-term benefits of satiety}

Benefits of longer-term (i.e. enduring) effects of dietary patterns and specific foods on appetite should translate into increased adherence to any prescribed dietary routine, if foods are acceptable to the consumer (i.e. perceived as tasty and delivering a discernible satiety benefit). Finding ways to manage hunger could improve dietary compliance. However, seldom is appetite measured systematically and frequently, using validated methods, during weightloss interventions. Rather, it is assumed that changes in appetite observed in acute dosing or chronic dosing studies translate into long-term weight-control benefits.

This leads to an interesting question - does a satiety benefit have to be enduring for a food to be beneficial in long-term weight management? For manufactured food products carrying claims the current regulatory perspective asserts that it must ${ }^{(11)}$. Presumably, however, there are tangible benefits even if the product works only in the short term. If the product enables initial changes in appetite in the early stages of weight management this could be beneficial, for example, allowing suppression of the 
learned food cue sensitivity discussed earlier. Alternatively, consumers may adjust subsequent intake following relearning of meal size via conditioned satiety ${ }^{(165)}$. Still, there is potential for 'fading away' of the effect of the product, or an aversion to satiety enhancement ${ }^{(66)}$. However, it is not clear whether and under what circumstances satiety effects will dissipate. If sustainable, one of the potential benefits of satiety enhancement may be compliance with energy restriction or a specific diet plan, but it is not yet clear under what conditions any benefits of satiety enhancement will contribute to compliance or whether there is a tipping point beyond which the product no longer provides the same level of benefit. These are all questions that require systematic scrutiny, specifically in the light of criticisms of functional foods making claims on satiety enhancement ${ }^{(5)}$.

\section{Potential benefits of satiety: limitations of the} science to date

A consistent limitation observed across the scientific evidence reviewed here is that there have been insufficient studies conducted directly on the benefits of satiety to permit systematic research review. A common constraint noted across those experiments that have been conducted on satiety enhancement is that these are typically laboratory based and conducted in the short term. Single exposures during a test meal or a single day of a study limit the generalisability of the research to the repeated purchase and use of specific products over time. Few published studies on the effects of different foods on mood also include measurements of hunger and satiety, and few studies on weight loss assess (or report) hunger and changes in hunger across the period of energy restriction. Thus, a major limitation of the present review has been the paucity of studies to draw from in understanding the potential benefits of satiety enhancement and the inherent constraints associated with short-term, laboratory-based research.

There may be unintended negative consequences for mood if satiety-enhancing foods produce lethargy or if changes to the diet are radically different from the habitual diet. Optimal effects on satiety and on mood seem to be associated with foods that are not too filling and which are similar to foods already consumed habitually. The pleasure from eating foods may depend on achieving a subtle and expected degree of satiety and so there is a potential threshold beyond which satiety enhancement may produce aversive consequences. Whilst the focus of the present review has been on benefits of satiety, potentially detrimental effects of excessive fullness, distension or satiety enhancement are acknowledged but these are even less studied than the benefits of satiety.

There is always a significant disconnect between what is found in laboratory-based studies and the real-life challenges faced by consumers. Too few studies have attempted to bridge this divide and some studies have focused too much on single ingredients, pure nutrients or particular products rather than examining effects across the whole diet. There are numerous assumptions made within different studies of appetite, weight management and cognitive performance linked to specific ingredients or nutrient content, but these assumptions do not reflect real dietary habits. Even if foods are shown to enhance satiety this does not mean that consumers will necessarily follow through with an overall healthier diet or indeed a lowered total energy intake. Thus products may be shown to be optimally effective under certain conditions but consumers may not experience a net benefit either by lack of compliance to those specific conditions or by lack of adjustment within the overall diet. However, this lack of effectiveness reflects more on the consumer than on the product.

Despite these limitations there is sufficient evidence from existing studies to suggest benefits of foods and diets that promote satiety and convincing evidence from the use of pharmaceutical agents as a model of how satiety can be beneficial in weight control. Whilst the present review has thrown into sharp relief the many gaps in this area that remain to be filled, there are reasons to believe that satiety enhancement can convey benefits for consumers.

\section{Conclusions}

Surveys involving consumers indicate both a willingness to try foods with satiety claims and a need for foods to provide enhanced satiety ${ }^{(38)}$. There is clear evidence from laboratory-based research demonstrating satiety enhancement of various foods in single administrations. Also, there are probable benefits of satiety enhancement in assuaging hunger during energy restriction to reduce feelings of deprivation, and to increase self-efficacy. Consumers need a 'reason to believe ${ }^{,(42)}$ and this is likely to be based on experience with the product fulfilling the promise of feeling fuller for longer or keeping hunger at bay. Pleasure interacts with satisfaction from the food eaten to determine how much and whether that food will be selected again in the future; therefore, it is not sufficient that a food product with a satiety claim enhances satiety, it also has to taste good and has to be eaten several times to produce learning. Alleviation of hunger produces benefits to mood, and if these foods become part of the habitual diet they may be associated with improvements in mood. Consumers using such products over time have the prospect of benefits accruing including improvements in feelings of wellbeing, improved adherence to healthier diets and/or weight management.

Satiety benefits should be demonstrated using agreed methodological principles and established tools for determining satiety effects of foods ${ }^{(12)}$. These tools can be applied to measure and establish the effect sizes and 
conditions under which variation in satiety effects of foods or diets contributes to long-term outcomes. The present review has highlighted that these outcomes should not be restricted to the direct effects on weight loss or control, but rather should include the ability to comply with healthy eating or other weight-control strategies, or simply to manage hunger including dysphoria associated with hunger. In addition, the recent work of Bilman et al. ${ }^{(38)}$ indicates that products with substantiated added effects on satiety should be correctly positioned and seen as an adjunct to other wilful personal efforts, rather than a product 'promise, (9) . Further research would be of value to confirm and extend these results.

To date, much of the evidence has been derived from a variety of laboratory methods, the durability of which remains unknown. Such benefits must be demonstrated in the real world; this is where there is currently a gap between experimentation and application. Nevertheless, given the success observed from the administration of specific pharmacological compounds in managing hunger, there is reason to consider the potential for analogous benefits from satiety-enhancing foods incorporated into the overall diet for similar, albeit much subtler, benefits.

There is much to be done to demonstrate systematically short-term benefits of satiety in terms of pleasure, hunger reduction and mood and longer-term benefits for adherence to a healthy diet or complying with programmes to lose weight. The present review has raised many questions that remain to be tackled. If it is accepted that satiety enhancement can benefit the consumer, what is the durability of the effect; will there be adaptation either physiologically or behaviourally; can benefits to appetite, mood and cognition demonstrated in the short term translate to the longer term; and can satiety enhancement produce a sustainable benefit in the long term for a healthier diet or for weight control?

The evidence to date provides optimism that these questions will be addressed. Laboratory-based studies reveal convincing evidence of short-term benefits and large-scale whole-diet manipulations similarly demonstrate probable evidence for satiety enhancement contributing to hunger management and therefore to weight loss. However, evidence that satiety enhancement can produce significantly greater weight-loss success is currently inadequate. Similarly, there is a lack of systematic study of which consumers will benefit most from satiety enhancement and only possible evidence of satiety benefits to both mood and cognition. The evidence on the link between satiety enhancement and dietary adherence is as yet untested, but could offer scope for future research. Overall, the consumer deserves answers to these questions and evidence that is convincing to support specific dietary choices to obtain the full benefits of satiety enhancement.

\section{Acknowledgements}

This work was conducted by an expert group of the European branch of the International Life Sciences Institute (ILSI Europe). This publication was coordinated by Ms Athanasia Baka, Scientific Project Manager at ILSI Europe.

The expert group received finding from the ILSI Europe Eating Behaviour and Energy Balance Task Force. Industry members of this task force are listed on the ILSI Europe website at www.ilsi.eu.

For further information about ILSI Europe, please email info@ilsieurope.be or call +32 277100 14. The opinions expressed herein and the conclusions of this publication are those of the authors and do not necessarily represent the views of ILSI Europe or those of its member companies.

There are no conflicts of interest.

\section{References}

1. International Food Information Council (2007) Consumer attitudes toward functional foods: foods for health. http:// www.ific.org/research/foodandhealthsurvey.cfm (accessed July 2009).

2. Thomas S (2009) Satiety: feeling full. http://www.preparedfoods.com/articles/article-satiety-feeling-full-july-2009 (accessed February 2012).

3. Unilever (2006) US Strategic Segmentation Study (unpublished).

4. Danone (2008) TNS Sofres Marketing Survey "Hungry Moments" (unpublished industry documentation).

5. Blundell J (2010) Making claims: functional foods for managing appetite and weight. Nat Rev Endocrinol 6, 53-56.

6. Booth DA \& Nouwen A (2010) Satiety. No way to slim. Appetite 55, 718-721.

7. Bellisle F \& Tremblay A (2011) Satiety and body weight control. Promise and compromise. Comment on 'Satiety. No way to slim'. Appetite 57, 769-771.

8. Smeets P \& Van der Laan LN (2011) Satiety. Not the problem, nor a solution. Comment on 'Satiety. No way to slim'. Appetite 57, 772-773.

9. Mela DJ (2011) Satiety. Let's put claims in the right context. Comment on 'Satiety. No way to slim'. Appetite 57, 774-777.

10. de Graaf C (2011) Trustworthy satiety claims are good for science and society. Comment on 'Satiety. No way to slim'. Appetite 57, 778-783.

11. European Parliament and the Council of the European Union (2007) Corrigendum to Regulation (EC) No 1924/2006 of the European Parliament and of the Council of 20 December 2006 on nutrition and health claims made on foods. Off $J$ Eur Union L 12 (18 January), 1-16. http://eur-lex.europa.eu/ LexUriServ/LexUriServ.do?uri=OJ:L:2007:012:0003:0018:EN: PDF (accessed April 2013).

12. Blundell J, de Graaf C, Hulshof T, et al. (2010) Appetite control: methodological aspects of the evaluation of foods. Obes Rev 11, 251-270.

13. Womble LG, Williamson DA, Greenway FL, et al. (2001) Psychological and behavioral predictors of weight loss during drug treatment for obesity. Int J Obes 25, 340-345.

14. Markowitz JT, Butryn ML \& Lowe MR (2008) Perceived deprivation, restrained eating and susceptibility to weight gain. Appetite 51, 720-722.

15. Zijlstra N, Mars M, Stafleu A, et al. (2010) The effect of texture differences on satiation in 3 pairs of solid foods. Appetite 55, 490-497. 
16. Bertenshaw EJ, Lluch A \& Yeomans MR (2009) Dosedependent effects of beverage protein content upon short-term intake. Appetite 52, 580-587.

17. Lyly M, Liukkonen KH, Salmenkallio-Marttila M, et al. (2009) Fibre in beverages can enhance perceived satiety. Eur J Nutr 48, 251-258.

18. Tsuchiya A, Almiron-Roig E, Lluch A, et al. (2006) Higher satiety ratings following yogurt consumption relative to fruit drink or dairy fruit drink. J Am Diet Assoc 106, 550-557.

19. Hoch SJ \& Deighton J (1989) Managing what consumers learn from experience. J Market 53, 1-20.

20. Herman CP \& Polivy J (2008) External cues in the control of food intake in humans: the sensory-normative direction. Physiol Behav 94, 722-728.

21. Van Strien TJ, Frijters ER, Bergers GP, et al. (1986) The Dutch Eating Behavior Questionnaire (DEBQ) for assessment of restraint emotional and external eating behavior. Int $J$ Eat Disord 5, 295-315.

22. Lowe MR, Burtryn ML, Didie ER, et al. (2009) The Power of Food Scale: a new measure of the psychological influence of the food environment. Appetite 53, 114-118.

23. Cappelleri JC, Bushmakin AC, Gerber RA, et al. (2009) Evaluating the Power of Food Scale in obese subjects and a general population of individuals: development and measurement properties. Int J Obes 33, 913-922.

24. Lowe MR \& Butryn ML (2007) Hedonic hunger: a new dimension of appetite? Physiol Behav 91, 432-439.

25. Murray M \& Vickers Z (2009) Consumer views of hunger and fullness: a qualitative approach. Appetite 53, 174-182.

26. Wansink B (2004) Environmental factors that increase the food intake and consumption volume of unknowing consumers. Annu Rev Nutr 24, 455-479.

27. Mann T \& Ward A (2004) To eat or not to eat: implications of the attentional myopia model for restrained eaters. $J$ Abnorm Psych 113, 90-98.

28. Hetherington MM, Anderson AS, Norton GNM, et al. (2006) Situational effects on meal intake: a comparison of eating alone and eating with others. Physiol Behav 88, 498-505.

29. Brunstrom JM \& Mitchell GL (2006) Effects of distraction on the development of satiety. Br J Nutr 96, 761-769.

30. Wansink B (2006) Mindless Eating: Why We Eat More Than We Think. New York: Bantam Books Dell.

31. Framson C, Kristal AR, Schenk JM, et al. (2009) Development and validation of the mindful eating questionnaire. J Am Diet Assoc 109, 1439-1444.

32. Tylka TL (2006) Development and psychometric evaluation of a measure of intuitive eating. J Counseling Psychol 53, $226-240$.

33. Westenhoefer J, Stunkard AJ \& Pudel V (1999) Validation of the flexible and rigid control dimensions of dietary restraint. Int J Eat Disord 26, 53-64.

34. Petty RE \& Cacioppo JT (editors) (1986) Communication and Persuasion: Central and Peripheral Routes to Attitude Change. New York: Springer-Verlag.

35. Drichoutis AC, Lazaridis P \& Nayga RM (2006) Consumers' use of nutritional labels: a review of research studies and issues. Acad Marketing Sci Rev 9, 1-22.

36. Pothoulakim M \& Chryssochoidis G (2009) Health claims: consumers' matters. J Functional Foods 1, 222-228.

37. Leatherhead Food International (2010) The Perceived and Physiological Effects of Dietary Proteins and Peptides on Satiety. Leatherhead: Leatherhead Food Research.

38. Bilman EM, van Kleef E, Mela DJ, et al. (2012) Consumer understanding, interpretation and ascription of personal responsibility in relation to satiety-related claims. Appetite 59, 912-920.
39. Van Trijp HCM (2009) Consumer understanding and nutritional communication: key issues in the context of the new EU legislation. Eur J Nutr 48, S41-S48.

40. Dykes J, Brunner EJ, Martikainen PT, et al. (2004) Socioeconomic gradient in body size and obesity among women: the role of dietary restraint disinhibition and hunger in the Whitehall II study. Int J Obes 28, 262-268.

41. Health Survey for England (2010) Statistics on obesity physical activity and diet. Department of Health. http://www. ic.nhs.uk/statistics-and-data-collections (accessed February 2012).

42. Van Trijp HCM \& Van der Lans IA (2007) Consumer perceptions of nutrition and health claims. Appetite 48, 305-324.

43. Goldstone AP, Prechtl de Hernandez CG, Beaver JD, et al. (2009) Fasting biases brain reward systems towards highcalorie foods. Eur J Neurosci 30, 1625-1635.

44. Booth DA (2009) The basics of quantitative judgment. How to rate the strength of appetite for food and its sating. Appetite 53, 438-441.

45. Havermans RC (2011) "You say it's liking, I say it's wanting". On the difficulty of disentangling food reward in man. Appetite 57, 286-294.

46. Finlayson G \& Dalton M (2012) Current progress in the assessment of 'liking' vs. 'wanting' food in human appetite. Comment on "You say it's liking, I say it's wanting...". On the difficulty of disentangling food reward in man. Appetite 58, 373-378.

47. Booth DA, O'Leary G, Li LX, et al. (2011) Aversive viscerally referred states and thirst accompanying the sating of hunger motivation by rapid digestion of glucosaccharides. Physiol Behav 102, 373-381.

48. Hetherington MM (1996) Sensory-specific satiety and its importance in meal termination. Neurosc Biobehav Rev 20, $113-117$

49. Rozin P \& Gohar D (2011) The pleasures and memory of food and meals. In Handbook of Behavior, Food and Nutrition, pp. 659-672 [VR Preedy, RR Watson and CR Martin, editors]. New York: Springer.

50. Booth DA (1985) Food-conditioned eating preferences and aversions with interoceptive elements: conditioned appetites and satieties. Ann N Y Acad Sci 443, 22-41.

51. Zheng H, Lenard NR, Shin AC, et al. (2009) Appetite control and energy balance regulation in the modern world: rewarddriven brain overrides repletion signals. Int J Obes 33, Suppl. 2, S8-S13.

52. Ahn S \& Phillips AG (1999) Dopaminergic correlates of sensory-specific satiety in the medial prefrontal cortex and nucleus accumbens of the rat. J Neurosci 19, RC29.

53. Gibson EL \& Desmond E (1999) Chocolate craving and hunger state: implications for the acquisition and expression of appetite and food choice. Appetite 32, 219-240.

54. Gibson EL \& Wardle J (2003) Energy density predicts preferences for fruit and vegetables in 4-year-old children. Appetite 41, 97-98.

55. de Graaf C, Schreurs S \& Blauw YH (1993) Short-term effects of different amounts of sweet and nonsweet carbohydrates on satiety and energy intake. Physiol Behav 54, 833-843.

56. Booth DA, Mather P \& Fuller J (1982) Starch content of ordinary foods associatively conditions human appetite and satiation indexed by intake and eating pleasantness of starch-paired flavours. Appetite 3, 163-184.

57. Kern DL, Mcphee L, Fisher J, et al. (1993) The postingestive consequences of fat condition preferences for flavors associated with high dietary fat. Physiol Behav 54, $71-76$.

58. Gibson EL \& Brunstrom JM (2007) Learned influences on appetite and food intake: evidence in human beings. 
In Progress in Brain Research: Appetite and Body WeightIntegrative Systems and the Development of Anti-Obesity Drugs, pp. 271-300 [SJ Cooper and TC Kirkham, editors]. London: Elsevier.

59. Durlach PJ, Elliman NA \& Rogers PJ (2002) Drinking while thirsty can lead to conditioned increases in consumption. Appetite 39, 119-125.

60. de Graaf C (2011) Why liquid energy results in overconsumption. Proc Nutr Soc 70, 162-170.

61. Brunstrom JM \& Fletcher HZ (2008) Flavour-flavour learning occurs automatically and only in hungry participants. Physiol Behav 93, 13-19.

62. Yeomans MR (1996) Palatability and the micro-structure of feeding in humans: the appetizer effect. Appetite 27, 119-133.

63. Yeomans MR, Gray RW \& Conyers THB (1998) Maltodextrin preloads reduce food intake without altering the appetiser effect. Physiol Behav 64, 501-506.

64. Carbonnel F, Lemann M, Rambaud JC, et al. (1994) Effect of the energy density of a solid-liquid meal on gastricemptying and satiety. Am J Clin Nutr 60, 307-311.

65. Brunstrom JM \& Rogers PJ (2009) How many calories are on our plate? Expected fullness not liking determines meal-size selection. Obesity 17, 1884-1890.

66. Yeomans MR, Weinberg L \& James S (2005) Effects of palatability and learned satiety on energy density influences on breakfast intake in humans. Physiol Behav 86, 487-499.

67. Gibson EL \& Wardle J (2001) Effect of contingent hunger state on development of appetite for a novel fruit snack. Appetite 37, 91-101.

68. Zandstra EH, Stubenitsky K, De Graaf C, et al. (2002) Effects of learned flavour cues on short-term regulation of food intake in a realistic setting. Physiol Behav 75, 83-90.

69. O'Sullivan HL, Alexander E, Ferriday D, et al. (2010) Effects of repeated exposure on liking for a reduced-energy-dense food. Am J Clin Nutr 91, 1584-1589.

70. Brunstrom JM (2011) The control of meal size in human subjects: a role for expected satiety expected satiation and premeal planning. Proc Nutr Soc 70, 155-161.

71. De Graaf C, De Jong LS \& Lambers AC (1999) Palatability affects satiation but not satiety. Physiol Behav 66, 681-688.

72. Davis JF, Choi DL \& Benoit SC (2010) Insulin leptin and reward. Trends Endocrin Metab 21, 68-74.

73. Batterham RL, Ffytche DH, Rosenthal JM, et al. (2007) PYY modulation of cortical and hypothalamic brain areas predicts feeding behaviour in humans. Nature 450, 106-109.

74. Dossat AM, Lilly N, Kay K, et al. (2011) Glucagon-like peptide 1 receptors in nucleus accumbens affect food intake. J Neurosci 31, 14453-14457.

75. Figlewicz DP \& Sipols AJ (2010) Energy regulatory signals and food reward. Pharmacol Biochem Behav 97, 15-24.

76. Yeomans MR \& Mobini S (2006) Hunger alters the expression of acquired hedonic but not sensory qualities of food-paired odors in humans. J Exp Psychol Anim Behav Process 32, 460-466.

77. Rode E, Rozin P \& Durlach P (2007) Experienced and remembered pleasure for meals: duration neglect but minimal peak, end (recency) or primacy effects. Appetite 49, 18-29.

78. Barkeling B, Rossner S \& Sjoberg A (1995) Methodological studies on single meal food intake characteristics in normal-weight and obese men and women. Int J Obes 19 284-290.

79. de Castro JM \& Elmore DK (1988) Subjective hunger relationships with meal patterns in the spontaneous feeding-behavior of humans - evidence for a causal connection. Physiol Behav 43, 159-165.
80. Drapeau V, Blundell J, Therrien F, et al. (2005) Appetite sensations as a marker of overall intake. Br J Nutr 93, 273-280.

81. Drapeau V, King N, Hetherington M, et al. (2007) Appetite sensations and satiety quotient: predictors of energy intake and weight loss. Appetite 48, 159-166.

82. Flint A, Raben A, Blundell JE, et al. (2000) Reproducibility, power and validity of visual analogue scares in assessment of appetite sensations in single test meal studies. Int J Obes 24, 38-48.

83. Hulshof T, Degraaf C \& Weststrate JA (1993) The effects of preloads varying in physical state and fat content on satiety and energy intake. Appetite 21, 273-286.

84. Parker BA, Sturm K, MacIntosh C, et al. (2004) Relation between food intake and visual analogue scale ratings of appetite and other sensations in healthy older and young subjects. Eur J Clin Nutr 58, 212-218.

85. Porrini M, Crovetti R, Testolin G, et al. (1995) Evaluation of satiety sensations and food intake after different preloads. Appetite 25, 17-30.

86. Veldhorst MA, Nieuwenhuizen AG, Hochstenbach-Waelen A, et al. (2009) A breakfast with alpha-lactalbumin, gelatin, or gelatin plus TRP lowers energy intake at lunch compared with a breakfast with casein, soy, whey, or whey-GMP. Clin Nutr 28, 147-155.

87. Mattes R (1990) Hunger ratings are not a valid proxy measure of reported food intake in humans. Appetite 15, $103-113$.

88. Sadoul B, Schuring EAH, Mela DJ, et al. (2012) The relationship between appetite scores and food intake: an analysis based on 25 studies. Obes Facts 5, Suppl. 1, 62 (abstract 205).

89. Li M \& Cheung BMY (2009) Pharmacotherapy for obesity. Br J Clin Phamacol 68, 804-810.

90. Rolls BJ, Shide DJ, Thorwart ML, et al. (1998) Sibutramine reduces food intake in non-dieting women with obesity. Obes Res 6, 1-11.

91. Barkeling B, Elfhag K, Rooth P, et al. (2003) Short-term effects of sibutramine (Reductil) on appetite and eating behaviour and the long-term therapeutic outcome. Int $J$ Obes 27, 693-700.

92. Keim NL, Stern JS \& Havel PJ (1998) Relation between circulating leptin concentrations and appetite during a prolonged, moderate energy deficit in women. Am J Clin Nutr 68 , 794-801.

93. Doucet E, Imbeault P, St-Pierre S, et al. (2000) Appetite after weight loss by energy restriction and a low-fat diet-exercise follow-up. Int J Obes 24, 906-914.

94. Sumithran P, Prendergast LA, Delbridge E, et al. (2011) Longterm persistence of hormonal adaptations to weight loss. $N$ Engl J Med 365, 1597-1604.

95. Bellisle F, Dalix AM, De Assis MA, et al. (2007) Motivational effects of 12-week moderately restrictive diets with or without special attention to the Glycaemic Index of foods. Br J Nutr 97, 790-798.

96. Blaney PH (1986) Affect and memory: a review. Psychol Bull 99, 229-246.

97. Gibson EL \& Green MW (2002) Nutritional influences on cognitive function: mechanisms of susceptibility. Nutr Res Rev 15, 169-206.

98. Dye L \& Blundell J (2002) Functional foods: psychological and behavioural functions. Br J Nutr 88, Suppl. 2, S187-S211.

99. Lloyd HM, Green MW \& Rogers PJ (1994) Mood and cognitive performance effects of isocaloric lunches differing in fat and carbohydrate content. Physiol Behav 56, 51-57.

100. Lloyd HM, Rogers PJ, Hedderley DI, et al. (1996) Acute effects on mood and cognitive performance of breakfasts 
differing in fat and carbohydrate content. Appetite 27, 151-164.

101. Wells AS, Read NW \& Craig A (1995) Influences of dietary and intraduodenal lipid on alertness mood and sustained concentration. Br J Nutr 74, 115-123.

102. Wells AS \& Read NW (1996) Influences of fat energy and time of day on mood and performance. Physiology 59, 1069-1076.

103. Hoyland A, Dye L \& Lawton CL (2009) A systematic review of the effect of breakfast on the cognitive performance of children and adolescents. Nutr Res Rev 22, 220-243.

104. Polivy J (1996) Psychological consequences of food restriction. J Am Diet Assoc 96, 589-592.

105. Bandura A (1982) The assessment and predictive generality of self-percepts of efficacy. J Behav Ther Exp Psychiatry 13, 195-199.

106. Pearson N, Ball K \& Crawford D (2011) Predictors of changes in adolescents' consumption of fruits vegetables and energy-dense snacks. Br J Nutr 105, 795-803.

107. Bas M \& Donmez S (2009) Self-efficacy and restrained eating in relation to weight loss among overweight men and women in Turkey. Appetite 52, 209-216.

108. Wamsteker EW, Geenen R, Iestra J, et al. (2005) Obesityrelated beliefs predict weight loss after an 8-week lowcalorie diet. J Am Diet Assoc 105, 441-444.

109. Clark MM \& King TK (2000) Eating self-efficacy and weight cycling: a prospective clinical study. Eat Behav 1, 47-52.

110. Duckworth LC, Gately PJ, Radley D, et al. (2009) RCT of a high-protein diet on hunger motivation and weight-loss in obese children: an extension and replication. Obesity 17, 1808-1810.

111. Klem ML, Wing RR, McGuire MT, et al. (1997) A descriptive study of individuals successful at long-term maintenance of substantial weight loss. Am J Clin Nutr 66, 239-246.

112. Karlsson J, Hallgren P, Kral J, et al. (1994) Predictors and effects of long-term dieting on mental well-being and weight loss in obese women. Appetite 23, 15-26.

113. Bryant EJ, King NA \& Blundell JE (2008) Disinhibition: its effects on appetite and weight regulation. Obes Rev $9,409-419$.

114. Das SK, Saltzman E, Gilhooly CH, et al. (2009) Low or moderate dietary energy restriction for long-term weight loss: what works best? Obesity 17, 2019-2024.

115. Teixeira PJ, Silva MN, Coutinho SR, et al. (2010) Mediators of weight loss and weight loss maintenance in middle-aged women. Obesity 18, 725-735.

116. Delzenne N, Blundell J, Brouns F, et al. (2010) Gastrointestinal targets of appetite regulation in humans. Obes Rev 11, 234-250.

117. Oliván B, Teixeira J, Bose M, et al. (2009) Effect of weight loss by diet or gastric bypass surgery on peptide YY3-36 levels. Ann Surg 249, 948-953.

118. Le Roux C, Patterson M, Vincent RP, et al. (2005) Postprandial plasma ghrelin is suppressed proportional to meal calorie content in normal-weight but not obese subjects. J Clin Endocrin Metab 90, 1068-1071.

119. de Luis DA, Sagrado MG, Conde R, et al. (2008) Changes of ghrelin and leptin in response to hypocaloric diet in obese patients. Nutrition 24, 162-166.

120. Heinonen MV, Laaksonen DE, Karhu T, et al. (2009) Effect of diet-induced weight loss on plasma apelin and cytokine levels in individuals with the metabolic syndrome. Nutr Metab Cardiovasc Dis 19, 626-633.

121. Lejeune MP, Hukshorn CJ, Saris WH, et al. (2007) Effects of very low calorie diet induced body weight loss with or without human pegylated recombinant leptin treatment on changes in ghrelin and adiponectin concentrations. Physiol Behav 91, 274-280.
122. Drazen DL, Vahl TP, D'Alessio DA, et al. (2006) Effects of a fixed meal pattern on ghrelin secretion: evidence for a learned response independent of nutrient status. Endocrinology 147, 23-30.

123. Chearskul S, Delbridge E, Shulkes A, et al. (2008) Effect of weight loss and ketosis on postprandial cholecystokinin and free fatty acid concentrations. Am J Clin Nutr 87, $1238-1246$.

124. Degen L, Drewe J, Piccoli F, et al. (2007) Effect of CCK-1 receptor blockade on ghrelin and PYY secretion in men. Am J Physiol Regul Integr Comp Physiol 292, R1391-R1399.

125. Chan JL, Stoyneva V, Kelesidis T, et al. (2006) Peptide YY levels are decreased by fasting and elevated following caloric intake but are not regulated by leptin. Diabetologia 49, 169-173.

126. Geliebter A, Schachter S, Lohmann-Walter C, et al. (1996) Reduced stomach capacity in obese subjects after dieting. Am J Clin Nutr 63, 170-173.

127. Raynor HA \& Epstein LH (2003) The relative-reinforcing value of food under differing levels of food deprivation and restriction. Appetite 40, 15-24.

128. Epstein LH, Truesdale R, Wojcik A, et al. (2003) Effects of deprivation on hedonics and reinforcing value of food. Physiol Behav 78, 221-227.

129. Dumesnil JG, Turgeon J, Tremblay A, et al. (2001) Effect of a low-glycaemic index-low-fat-high protein diet on the atherogenic metabolic risk profile of abdominally obese men. Br J Nutr 86, 557-568.

130. Rodriguez-Rodriguez E, Aparicio A, Bermejo LM, et al. (2009) Changes in the sensation of hunger and well-being before and after meals in overweight/obese women following two types of hypoenergetic diet. Public Health Nutr 12, 44-50.

131. Pasman WJ, Saris WH \& Westerterp-Plantenga MS (1999) Predictors of weight maintenance. Obes Res 7, 43-50.

132. Franklin JC, Scheile BC, Brožek J, et al. (1948) Observations on human behavior in experimental semi-starvation and rehabilitation. J Clin Psychol 4, 28-45.

133. Lowe MR (1993) The effects of dieting on eating behavior: a three-factor model. Psychol Bull 114, 100-121.

134. Lieberman HR, Caruso CM, Niro PJ, et al. (2008) A doubleblind, placebo-controlled test of $2 \mathrm{~d}$ of calorie deprivation: effects on cognition, activity, sleep, and interstitial glucose concentrations. Am J Clin Nutr 88, 667-676.

135. Hill AJ (2007) The psychology of food craving. Proc Nutr Soc 66, 277-285.

136. Harvey J, Wing RR \& Mullen M (1993) Effects on food cravings of a very low calorie diet or a balanced, low calorie diet. Appetite 21, 105-115.

137. Martin CK, O'Neil PM \& Pawlow L (2006) Changes in food cravings during low-calorie and very-low-calorie diets. Obesity 14, 115-121.

138. Burley VJ, Kreitzman SN, Hill AJ, et al. (1992) Acrossthe-day monitoring of mood and energy intake before, during and after a very-low-calorie diet. Am J Clin Nutr 56, Suppl. 1, 277S-278S.

139. Gibson EL (2011) Emotional and behavioral aspects of chocolate eating. In Handbook of Behavior, Food and Nutrition, pp. 601-620 [VR Preedy, RR Watson and CR Martin, editors]. New York: Springer.

140. Nederkoorn C, Guerrieri R, Havermans RC, et al. (2009) The interactive effect of hunger and impulsivity on food intake and purchase in a virtual supermarket. Int $J$ Obes 33, 905-912.

141. Jones N \& Rogers PJ (2003) Preoccupation, food, and failure: an investigation of cognitive performance deficits in dieters. Int J Eat Disord 33, 185-192. 
142. Kemps E, Tiggemann M \& Grigg M (2008) Food cravings consume limited cognitive resources. J Exp Psychol Appl 14, 247-254

143. Stewart SH \& Samoluk SB (1997) Effects of short-term food deprivation and chronic dietary restraint on the selective processing or appetitive-related cues. Int $J$ Eat Disord 21, 129-135.

144. Francis JA, Stewart SH \& Hounsell S (1997) Dietary restraint and the selective processing of forbidden and nonforbidden food words. Cogn Ther Res 21, 633-646.

145. Stockburger J, Schmälzle R, Flaisch T, et al. (2009) The impact of hunger on food cue processing: an event-related brain potential study. Neuroimage 47, 1819-1829.

146. Timmerman GM \& Gregg EK (2003) Dieting, perceived deprivation, and preoccupation with food. West J Nurs Res 25, 405-418.

147. Anderson IM, Parry-Billings M, Newsholme EA, et al. (1990) Dieting reduces plasma tryptophan and alters brain 5-HT function in women. Psychol Med 20, 785-791.

148. Bryan J \& Tiggemann M (2001) The effect of weight-loss dieting on cognitive performance and psychological well-being in overweight women. Appetite 36, 147-156.

149. Halford JC, Boyland EJ, Blundell JE, et al. (2010) Pharmacological management of appetite expression in obesity. Nat Rev Endocrinol 6, 255-269.

150. Hill AJ, Lawton CL, Wales JK, et al. (1995) Dexfenfluramine and the control of eating: effects on obese women living at home. Int J Obes 19, Suppl. 2, 142 (abstract).

151. Dixon AFR, Dixon JB \& O'Brien PE (2005) Laparoscopic adjustable gastric banding induces prolonged satiety: a randomized blind crossover study. J Clin Endocrinol Metab 90, 813-819.

152. Karamanakos SN, Vagenas $\mathrm{K}$, Kalfarentzos $\mathrm{F}$, et al. (2008) Weight loss appetite suppression and changes in fasting and postprandial ghrelin and peptide-YY levels after Roux-en-Y gastric bypass and sleeve gastrectomy: a prospective double blind study. Ann Surg 247, 401-407.

153. Halton TL \& Hu FB (2004) The effects of high protein diets on thermogenesis satiety and weight loss: a critical review. J Am Coll Nutr 23, 373-385.

154. Paddon-Jones D, Westman E, Mattes RD, et al. (2008) Protein weight management and satiety. Am J Clin Nutr 87, 1558S-1561S.
155. Weigle DS, Breen PA, Matthys CC, et al. (2005) A highprotein diet induces sustained reductions in appetite ad libitum caloric intake and body weight despite compensatory changes in diurnal plasma leptin and ghrelin concentrations. Am J Clin Nutr 82, 41-48.

156. Nickols-Richardson SM, Coleman MD, Volpe JJ, et al. (2005) Perceived hunger is lower and weight loss is greater in overweight premenopausal women consuming a lowcarbohydrate/high-protein vs high-carbohydrate/low-fat diet. J Am Diet Assoc 105, 1433-1437.

157. Due A, Toubro S, Skov AR, et al. (2004) Effect of normal-fat diets either medium or high in protein on body weight in overweight subjects: a randomised 1-year trial. Int J Obes 28, 1283-1290.

158. Johnstone AM, Horgan GW, Murison SD, et al. (2008) Effects of a high-protein ketogenic diet on hunger, appetite and weight loss in obese men feeding ad libitum. Am J Clin Nutr 87, 44-55.

159. Westerterp-Plantenga MS, Lejeune MP, Nijs I, et al. (2004) High protein intake sustains weight maintenance after body weight loss in humans. Int J Obes 28, 57-64.

160. Kovacs EM, Westerterp-Plantenga MS, Saris WH, et al. (2001) The effect of addition of modified guar gum to a low-energy semisolid meal on appetite and body weight loss. Int J Obes 25, 307-315.

161. Greenway F, O'Neil CE, Stewart L, et al. (2007) Fourteen weeks of treatment with Viscofiber increased fasting levels of glucagon-like peptide-1 and peptide-YY. J Med Food 10, 720-724.

162. Salas-Salvadó J, Farrés X, Luque X, et al. (2008) Effect of two doses of a mixture of soluble fibres on body weight and metabolic variables in overweight or obese patients: a randomised trial. Br J Nutr 99, 1380-1387.

163. Wanders AJ, van den Borne JJ, de Graaf C, et al. (2011) Effects of dietary fibre on subjective appetite, energy intake and body weight: a systematic review of randomized controlled trials. Obes Rev 12, 724-739.

164. Anton SD, Han H, York E, et al. (2009) Effect of calorie restriction on subjective ratings of appetite. J Hum Nutr Diet 22, 141-147.

165. Booth DA (1977) Satiety and appetite are conditioned reactions. Psychosom Med 39, 76-81. 